\title{
CIENCIA POLITICA
}

\section{Nota Introdutória a uma Sociologia dos Governantes}

\section{Georges Burdeau}

\begin{abstract}
A renovação da Ciência Política - ccmprovada pelo aparecimento da Revista Francesa de Ciência Politica (*) - leva a considerar, sob uma luz mais propícia, os problemas que, outrora, pareciam prender-se exclusivamente à simples técnica constitucional. Foi em data ainda muito recente que nos apercebemos de que a análise da estrutura das instituições só fornecia esclarecimentos por demais intempcrais para explicar c caráter dos regimes democráticos, hipotéticamente baseados sôbre as atitudes políticas de todos os homens. A observação do con.portamento do homem real em face dos mecanismos políticos, - cujo funcionamento pressupõe, de sua parte, uma atividade voluntária - teve, assim, por conseqüência, humanizar o Direito Constitucional, pois que o arrancou às seduções de uma espécie de teologia política a que êle se sentia por demais inclinado a ceder.
\end{abstract}

Nossas preocupações foram, no entanto, até então, especialmente com as reações dos governados. A Sociclogia Política cristalizara-se em tôrno do fenômeno da eleição, e de tal modo que c estudo da formação das opiniões, a observação dos partidos, a análise dos fatôres atuantes sôbre a mentalidade coletiva, erair: versados, em geral, em função da operação eleitoral. Êsse método se explicaria perfeitamente, desde que admitíssemos que, num sistema representativc, á ação política é desencadeada, crientada e sancionada pela eleição. No entanto, se uma tal preocupação devesse monopolizar as pesquisas ida Sociologia Política esta se arriscaria a não cultivar um campo pràticamente ainda virgem - mas de uma riqueza que fàcilmente se adivinha e que é determinado pela mentalidade política dos gov rnantes. Já não estamcs dispostos, hoje em dia, a aceitar, como dado objetivo, o sentido e o valor das instituições. Sabemos que os seus próprios efeitos são tributários menos da finalidade a que teòricamente elas se destinem, do que do caráter e dos reflexos do pessoal político que lhes há de assegurar o emprêgo. Nenhuma "objetividade científica" autorizaria, por exemplo, a formular a teoria da responsabilidias ministerial ou da dissolução do Parlamento, abstraindo do meio onde se supõe que essas instituições devam atuar; a objetividade, no caso, só nos conduziria a um contra-senso.

(*) Este ensaio foi criginàriamente publicado na Revue Française de Science Politique (vo1. I, ns. 1-2, Jan. - Jun., 1951); sua tradução foi feita na Redação da Revista do Serviço Público, que agradece ao Serviço de Imprensa da Embaixada da França a boa voritade com que nos autorizou a divulgá-lo. 
Nessas condições, se as formas espontâneas da vida política, muito mais que os quadros jurídicos aistratos, estabelecidos pelas constituições, é que proporcionam aos regiñes sua originalidade e às instituições, seu alcance, uma sociologia dos governantes se torna indispensável para fornecer à Ciência Política os elementos de um estudo realista. O real são os parlamentares, os ministr os, as comissões; as regras constitucionais - ainda que necessárias e imperativas - não escapam à característica que thes imprime essa realidade, que por elas é enquadrada. No entanto, se a oportunidade de uma sociologia dos governantes parece, à primiera vista, indiscutível, uma reflexão mais atenta desperta imediatamente as suas dificuldades. Ainda que deixando de iparte as que se relacionam com a delicadeza da informação e que, em graus diferentes, são inerentes a tôda ciência social, deparamo-nos com outras que, então, se prendem ao próprio princípio da pesquisa empreendida. Trata-se, com efeito, de determinar, por um lado, os sujeitos cujo comportamento seja uma causa e, por outro lado, de prescrever a essa Sociologia governamental objetivos precisos.

Sôbre o primeirc: ponto, a hesitação se prende ao fato de que as personalidades governantes são, por hipótese, fortemente individualizadas. Sem querer atribuir a todos um destino extracrdinário - o que seria exagêro, talvez lisonjeiro, mas abusivo - cumpre recrnnhecer que nos bancos das assembléias e nos conselhos governamentais se enccntra uma proporção de individualidades marcantes mais elevada do que na média dos grupos estudados habitualmente pela sociologia. Poder-se-á então, atendendo-se a tais originalidades, atenuarlhes o relêvo em umá coletividade indivisa, que será objeto de análise da mesma espécie da que se aplica à multidão anônima de eleitcres, ao público de um meeting ou de manifestaçãc esportiva?

A objeção parece, à primeira vista, decisiva, do mesno passo que explica a ausência de qualquer empreendimento do gênero que preconizamos. Sente-se a falta de uma sociologia dos governantes porque 0 objeto a ela não se coaduna. Mas, será assim tão evidente? E, à falta de sociologia, a ciência política acaso não poderá preservar - - senão $c$ que escapa em uma poderosa personalidade de homem de Estado à possibilidade das classificaçõeş - pelo menos o alcance que sua presença deu às instituições, a inflexão que seu temperamento imprimiu aos costumes políticos?

Sem dúvida, não se trata de aplicar métodos estatísticos aos hor.ens políticos, cujos lugares na história se definem precisamente pela singularidade de seus reflexos ou pela criginalidade de seu talento. Nem DisRaELI, nem Cavour, nem THIERs podem fornecer matéria a estudo sociológico. A estatura com que êles se nos apresentam, isolando-os do grupo, não permite que se dobrem à lei dos grandes números. Neste caso é sobretudo a história que tem competência e, se se pretende condimentá-la com um grão de filosofia, será EMERSON ou CARLyLE que o fornecerão e não DURKhEIM ou M. MAUSS. No entanto, a Ciência Política ficaria perigosamente empobrecida se excluísse do seu campo de pesquisa a personalidade dos chefes, e a própria Sociologia se exporia a graves erros de julgamento se pretendesse, por um postulado puerilmente democrático, não se voltar senão para c tipo médio, para o anônimo ou para 
o indiferenciado. Tanto para uma como para outra dessas disciplinas a questão não é de negar ou de ignorar êsses destinos excepcionais, mas de reintegrá-los, sempre que a operação fôr possível, no meio em que são soberanos: DisRaELI, na Câmara dos Comuns; Cawour, no parlamento de Turim; THIERS, na Assembléia Nacional de 1871. Então, sem arrebatar ao historiador a personalidade e a obra do homem, a Ciência e a Sociologia Políticas sentir-se-ão qualificadas para apreender, através do meio que êle marcou, a influência que o horrem exerceu sôbre as instituições.

1. Antes de tudo, é certo que, do ponto de vista da Ciência política, se torna do mais alto interêsse delimitar, na gênese das formas governamentais, a parte que cabe, respectivamente, às teorias e às considerações pessoais. Que o temor de ver Mirabeau na situação de Ministro tenha pesado mais fortemente que o respeito ao princípio da separação dos poderes, quando os Constituintes de 1791 decidiram vedar ao Rei a escolha de seus ministros na Assembléia; que o recurso imoderado à questão de confiança da parte de PoINCARÉ ou de um dos seus sucessores tenha incitado cs Constituintes de 1946 à desconfiança relativamente a um processo suscetível de ser desviado de sua razão de sar racional; que o temperamento de FrANKLIN Roosevelt tenha contribuído para um tão profundo rejuvenescimento das instituições americanas a ponto de a Constituição de Filadélfia ficar de fato totalmente renovada - eis alguns fatos que nos levam a considerar as virtudes das teorias constitucionais com um são relativismo. E' verdade que de há muito os publicistas se habituaram a prolongar o estudo dos textos pela prática que êles criginam, mas trata-se, neste caso, menos de uma prática anônima e coletiva do que da ação exercida por um pequeno número de indivíduos e motivados por seu caráter, por suas habilidades ou fraquezas. A vida pública se processa, destarte, por uma combinação entre as regras e o temperamento daqueles que, pela sua atitude, thes fixam o sentido. Seria útil, portanto, analisar êsse fator humano na medida mesma em que dêle procede o espírito das instituições.

2. Do ponto de vista da Sociologia, ademais, não é duvidoso que ela tenha ccmpetência para observas as condições em que as instituições formam as personalidades dirigentes. A democracia não aceita seus chefes do exterior: ela os cria para si mesma; se ela thes concede muito, ainda thes pede mais; ela quer reconhecer-se nêles e, nc entanto, êles devem trazer sua contribuição pessoal. Daí, uma dosagem extremamente sutil dos elementos constitutivos da situação política dos governantes. Seria do mais alto interêsse procurar pesquisar como as instituições representativas suscitam líderes - antes de tudo, pela eleição e, em seguida, pelo caráter dos debates nas assembléias, pela atmosfera parlamentar e pela psicologia dos grupos políticos - e como elas os dintinguem com o seu sêlo. Está amplamente evidenciado que grandes espíritos, como um BARRÉS ou um LÉON BLUM, por exemplo, sempre se sentiram estranhos às Câmaras onde tinham assentc. Outros, que pelo seu próprio estôfo não se thes equiparavam, realizaram nessas mesmas Câmaras carreiras impressionantes. Existern, portanto, conexões e repulsões entre o meio e os temperaimentos individuais. O meio secreta a sua elite ou pelo menos a escolhe. A Sociologia poderia prestar à Ciência Política um serviço de extraordinária relevância se se voltasse para a descrição e, depois, para a sistematização dos fatôres que deveriam gerar os agentes governamentais adaptados às exigências 
do regime. Sabe-se confusamente que não basta que um homem tenha passado pelo crivo legal da consecução do poder para que seja aceito comum líder cumpre que êle traga consigo o que nem a eleição nem a investidura dos grupos lhe poderia conferir, isto é, uma misteriosa disposição para pensar e reagir segundo o espírito da democracia. Ora, o meio raramente se engana sôbre essa disposição, e adota cu refuga as personalidades marcantes conforme disponham elas ou não dessa qualidadì; discerne as promessas, assim como a colmeia distingue a rainha; encoraja-as, ajuda a ascensão daqueles a que de bom grado se submete; em suma, prepara o chefe adaptando o homem às instituições. E quandc se pensa no que será a sua influência sôbre as formas de atividade governamental, tem-se a exata medida do interêsse que haveria em conhecer, sem apelar para intuições fugazes, o processo de aparecimento dos dirigentes pelc jôgo da ambiência política.

\section{II}

Mas o próprio meio - quando o consideramos não mais em função das personalidades que dêle se destacam, mas no seu anonimato, como massa indiferenciada - também é mal conhecido em seu comportamento coletivo. Ainda neste caso, səria indispensável um estudo sociológicc para corrigir ou completar o que panfletos do gênero - República dos professôres, República dos camaradas ou Suas fisionomias (*) - por muito perspicazes que sejam, têm de arbitràriamente subjetivo ou de exageradamente sumário.

O primeiro ponto a esclarecer seria pesquisar se existe, entre os membros de unta assembléia, uma solidariedade que, vencidas as divergências de posição palítica, lhes dá o sentimento de pertencerem a uma corporação que desfruta, como tal, de direitcs e de prerrogativas e se desincumbe de suas responsabilidades. A qualidade de eleito do povo, que foi tão sensível nas primeiras assembléias representativas, acaso sobreviveu à influência cada vez mais pesada que cs partidos exercem sôbre os eleitos? Se a resposta fôr afirmativa, as câmaras continuam, sociològicamente, formações autônomas, dotadas de um psquismo próprio e capazes de exercer a autoridade constitucionalmente associada à sua função. Se a respcsta, no entanto, fôr negativa, a pulverização e a dissociação da corporação só deixam subsistir rivalidades de pessoas e concorrências de interêsses, em que se dissolve a unidade da representação nacional. Considierado dêsse ângulo, o problema clássico da oposição entre o mandato imperativo e o mandato representativo ficaria rejuvenescido ao mesmo tempo que subtraído às soluções exclusivamente dogmáticas. E' bom fixar os caracteres constitucionais do mandato, mas não é inútil, tampouco, que nos preocupemos com as condiçc̃es sociológicas que o meio pressupõe para seu exercício por isto que é dêle que emergirá, ao cabo de contas, a fisioncrnia real do mandato.

A esta altura, precisamente, seria oportuno enriquecer a noção jurídica de representante pelo estudo da realidade física, psicológica e moral que ela recobre. As estatísticas se limitam, geralmente, a nos infornar sôbre o nível

(*) Livros de autoria, respectivamente, de Albert Thibaudet, Raymond Aron e MAURICE BARRÈS. 
dos estudos realizados pelos eleitos, sôbre o seu meio social e profissão. São dados úteis, mas que exigiriam complementação por uma análise da mentalidade e dos temperamentos. E' incontestável que a profissão parlamentar postula, nos que a ela se dedicam, um certo número de dispesições, qualidades e defeitos que, a despeito das opiniões, contribuem para criar uma espécie de deformaçao profissional. Serão êsses traços característicos suficientemente precisos e generalizados, para que se possa, tomando-os como ponto de partida, discernir a existência de um tipo social? Em caso afirmativo, do que não podemos absolutamente duvidar, êsse tipo, que certamente tem evoluído com as épocas (dos notáveis, por exemplo, às novas camadas) terá sido porventura infiuenciado pelas instituiçôes (eleitorais cu cutras) e sôbre elas terá agid: (as transformações das reiações er tre a naaioria $\epsilon$ cposição en: virtude de uma mudança nas espécies de parlamentares)? Enfim, quais são os traços dominantes dêsse tipo com que mais ou menos se relacionam todos os que se envolvem com a coisa pública? Partindo-se dos resultados de tal inquérito, poder-se-ia constituir uma sociologia das assembléias, suas lições enriqueceriam oportunamente o conhecimento das instituições pela observação das fôrças que as movimentam e, sem dúvida, poder-se-ia ainda promover a revisão da concepção racional de democracia, regime abertc a todos pela verificação de que efetivamente, suas personalidades dirigentes pertencem a uma família espiritual ou a um grupo psicológico, cujas características são precisamente as exigidas pelo funcionamento da" instituições representativas.

Sem pretender indicar aqui todos os campos em que o método sociclógico, quando aplicado e.c pessoal governante, seria suscetível de conduzir a in portantes descobertas, cumpre assinalar um ponto onde - ao que parece - êle deverá ser particularmente frutífero. Trata-se da consciência que as assernbléias têm de sua posição e do papel que representam relativamente à opinião.

A eficácia do regime representativo depende da sensibilidade dos parlamentos às variações da opinião; seria oportuno, conseguintemente, apreciar o grau dessa sensibilidade confrontando as posições globais da assembléia com os movimentos de opinião suscitados por um grande problema nacional (Munique, rearmamento da Alemanha, por exemplo). Poder-se-ia, então, procurar saber se os eleitos estão ligados definitivamente às teses dos partidos ou se, pelo contrário, são capazes na eventualidade do crises graves, de entrar novamente em contato com uma vontade e uma emoçãc popular espontâneas. No mesmo sentidc, uma análise dos comportamentos coletivos permitiria medir a aptidão dos órgãcs deliberativos a exprimir o que os teóricos chamam. de vontade nacional. Caberia, então, proceder à verificação ou à infirmação sociológica dos princípios constitucionais. Que vale, por exemplo, a condenação doutrinal do processo dos Decretos-leis se a abnegação e a coragem cívicas, que dão às assembléias a fôrça de resistir à sedução que êles apresentam, são, sociològicaniente, impossíveis? Semelhantemente, onde localizar os elementos constitutivos do fenômeno conhecido scib o rótulo de ascensão das massas sem fazer referência às atitudes dos que participam do Govêrno? Os textos de nada servem, por isto que nenhur.a diferença de redação permite distinguir a passagem da democracia individualista para a democracia da massa. Quanto ao estado de espírito dos governados, não tem êle possibilidade de ser decisivo iserão na medida em que os governantes subscrevem as suas exigências. Daí 
a indagação: que íatôres predispõem uma assembléia a tornar-se instrumento de um regime de massa? Permeabilidade às modas em questões de filosofia social, conflito entre a preocupação da reeleição e a vontade de salvaguardar a independéncia de julgan.ento, passividade em relação às ideologias partidárias, aptidãn para acompanhar ou vontade de guiar, inclinação para as soluções fáceis. . . Eis um campo vastíssimo de investigação para uma sociologia que se oriente em consonância com as preocupações da ciência política. O Direito Constitucional construiu, com as idéias, a teoria da democracia; cabe à Sociologia apresentar-nos, com os homens, a da demagogia. Apercebida dos painéis do díptico, a Ciência Política está, então, em condições de fazer a sintese das duas para definir o regime real. 